\title{
Research on the combined effects of traditional Chinese medicine compound Based on physical movement Theory
}

\author{
Changlei $\mathrm{Li}^{1}$, Xiaoqing Chen ${ }^{1}$, Huiling $\mathrm{Yi}^{1}$, Zhe Xiong ${ }^{1}$, and Baomiao $\mathrm{Ma}^{1, *}$ \\ ${ }^{1}$ School of medicine, Jianghan University, Wuhan Hubei China
}

\begin{abstract}
Methamphetamine (METH) is a powerful psychostimulant. Chronic obsessive and compulsive usage of METH caused great harm to human health (physical and psychological) and social stability issues all over the world. Currently, no drugs have been used to treat and prevent METH addiction. Our previous studies demonstrated that Chinese medicine compound (JDYH) can inhibit METH-induced sensitization in mice. To investigate the combined effects of JDYH on physical movement in C57BL/6 male mice. In the experiment, mice chronic treatment with JDYH (14.12-56.48 g/ kg) for 28-30 days, physical movement activity and body weight was measured. The body weight and physical movement have no change after being treated with low-dose $(14.12 \mathrm{~g} / \mathrm{kg})$ and mid-dose $(28.24 \mathrm{~g} / \mathrm{kg})$ of chronic treatment with JDYH. These results suggest that JDYH (14.12-28.24 g/kg) for 21 days were not inhibit physical movement in mice.
\end{abstract}

\section{INTRODUCTION}

Methamphetamin(METH) is a addictive substance that has a potent effect on the central nervous system[1-3]. Chronic use of Methamphetamine contributes a societal burden by increasing health care costs and crime, psychomotor dysfunction and ultimately irreversible damage to human body [4-7]. There is currently no effective drug treatment for addiction. Thus, it has great actual meaning for finding and developing medications to treat and prevent METH dependence. Therefore, it is of great significance to seek effective and low-toxicity intervention drugs for the clinical treatment of METH addicts. In recent years, Traditional Chinese medicine has attracted much attention of research field because of its long clinical use and reliable therapeutic effect.

Chinese medicine compound is widely used to develop effective new drugs[8, 9], and our team designed a novel medicinal compounds Jieduyihao (JDYH) with eight ingredients, such as yanhusuo, Codonopsis pilosula, tractylodes macrocephala, Angelica sinensis, Licorice, Poriacocos, American ginseng and Panax quinquefolius. Our previous studies demonstrated that JDYH can inhibit METH-induced sensitization in C57BL/6 mice[10]. However, the effect of JDYH on physical movement remain unclear. The present study to assess the effects of JDYH on physical movement.

\section{MATERIALS AND METHODS}

\subsection{Animals}

\footnotetext{
* Corresponding author: mabm.whibs@jhun.edu.cn
}

Male C57BL/6 mice (18-21g, obtained from Beijing Vital River Laboratory Animal Technology Co.,Ltd., Beijing, China) were housed in each cage with and maintained in a temperature controlled room with a diurnal cycle of 12-h (turn on the lights at 20:00 and light off at 8:00) [11]. The mice had free access to water and food. All procedures were permitted by the Jianghan University Animal ethics committee.

\subsection{Chemicals and drugs}

The total weight of JDYH was 94g (each component of Chinese medicine was purchased from Hubei Tianji Chinese Medicine Decoction Pieces Company). Decoct the Chinese medicine in $1400 \mathrm{~mL}$ water to $400 \mathrm{~mL}$, concentrate the extract to the required concentration, and give the medicine by gavage.

\subsection{Body weight}

The mice in body weight test were divided into four groups $(\mathrm{n}=12-16)$. Each group pretreatment JDYH $(0$, $14.12,28.24,56.48 \mathrm{~g} / \mathrm{kg}$, i.g.) for 21 days. In conditioned place preference (CPP) experiments, mice were followed by observation for an additional 7 days. The body weight of mice were recorded weekly (days 0,7 , 14, 21 and 28).

\subsection{Physical movement}

Fig. 1 shows the spontaneous activity device. The movement behavior of the mice was recorded by the animal spontaneous movement video analysis system, which consisted of eight equisized $(25 \mathrm{~cm} \times 25 \mathrm{~cm} \times 45 \mathrm{~cm}$, 
length $\times$ width $\times$ height) sound isolators, manufactured by Ningbo AnLai Technology Company. In this study, the test method in mice referred to the study [11-13]. The mice were divided into four groups $(\mathrm{n}=12-16)$. Each group chronic pretreatment JDYH $(0,14.12,28.24$, $56.48 \mathrm{~g} / \mathrm{kg}$, i.g.) for 21 days. In CPP experiments, mice were followed by observation for an additional 7 days. Then, all mice were transported to the chambers for a $15 \mathrm{~min}$ test.The physical movement of mice were recorded weekly (days 0, 7, 14, 21 and 30).

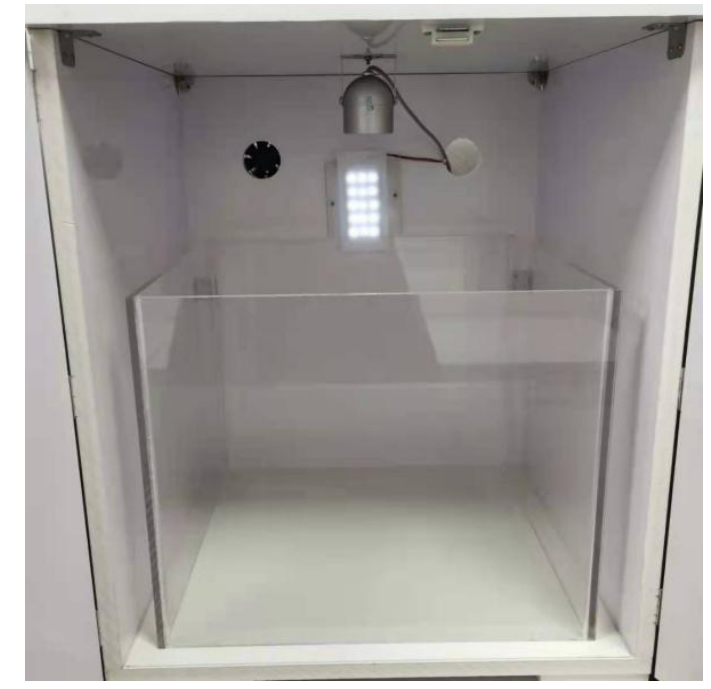

Figure.1. Spontaneous Activity of experimental animals

\subsection{Data analyses}

Data analysis by the software GraphPad Prism 8 was employed. Data were exhibited as mean values \pm S.E.M by using SPSS 18 software. The body weight and locomotor activity data were analyzed by one-way ANOVA followed by Dunnett's tests of difference from control values. The p-value threshold was 0.05 .

\section{RESULTS}

\subsection{Effects of JDYH on body weight}

In C57BL/6J mice, chronic treatment with JDYH (14.12$56.48 \mathrm{~g} / \mathrm{kg}$ ) for 28 days, on body weight in mice was examined and is shown in Fig.2. Analysis showed a no significant effect of chronic treatment with JDYH on body weight for 21 days $(\mathrm{p}>0.05)$, that JDYH treatment chronic treatment with at high doses of 56.48 $\mathrm{g} / \mathrm{kg}$ significantly decreased the body weight on $21 \mathrm{~d}$ $(\mathrm{p}<0.05)$.

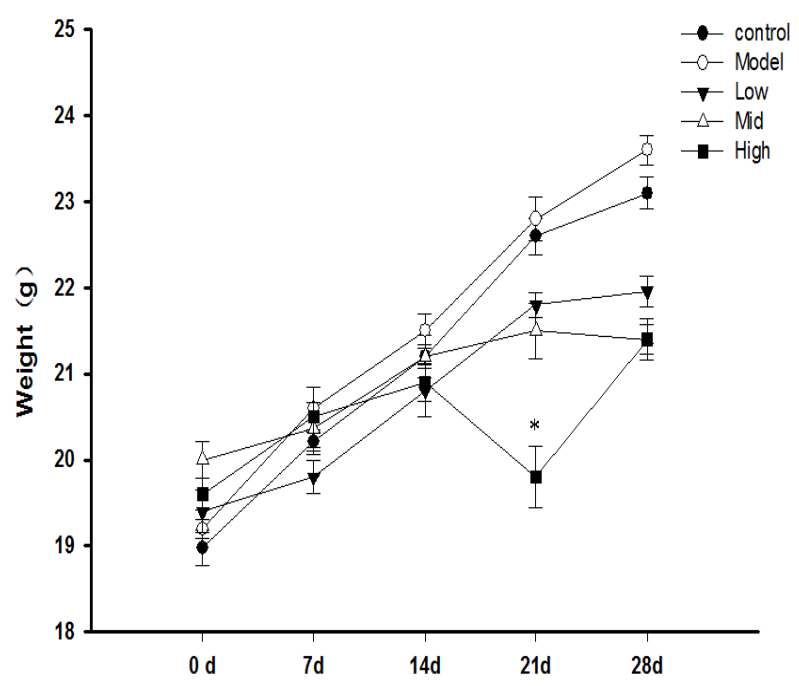

Fig.2. Effects of JDYH on body weight in mice ( $\mathrm{n}=12-16)$. Each group chronic pretreatment JDYH $(0,14.12,28.24$, $56.48 \mathrm{~g} / \mathrm{kg}$, i.g.) for 30 days. Statistically significant differences are indicated by $*(p<0.05)$.

\subsection{Effects of JDYH on physical movement}

The effect of JDYH (14.12-56.48 $\mathrm{g} / \mathrm{kg})$ on physical movement (total distance traveled $/ 15 \mathrm{~min}$ ) in mice during 30 days of chronic treatment is shown in Fig. 3. One-way ANOVA showed a significant main effect of JDYH treatment on locomotion activities and multiple comparisons showed that JDYH treatment chronic treatment with at high doses of $56.48 \mathrm{~g} / \mathrm{kg}$ significantly decreased the locomotion activities on $21 \mathrm{~d}(\mathrm{p}<0.05)$, and JDYH (14.12-28.24 g/ $/ \mathrm{kg})$ for 21days were not inhibit physical movement in mice $(\mathrm{p}>0.05)$.

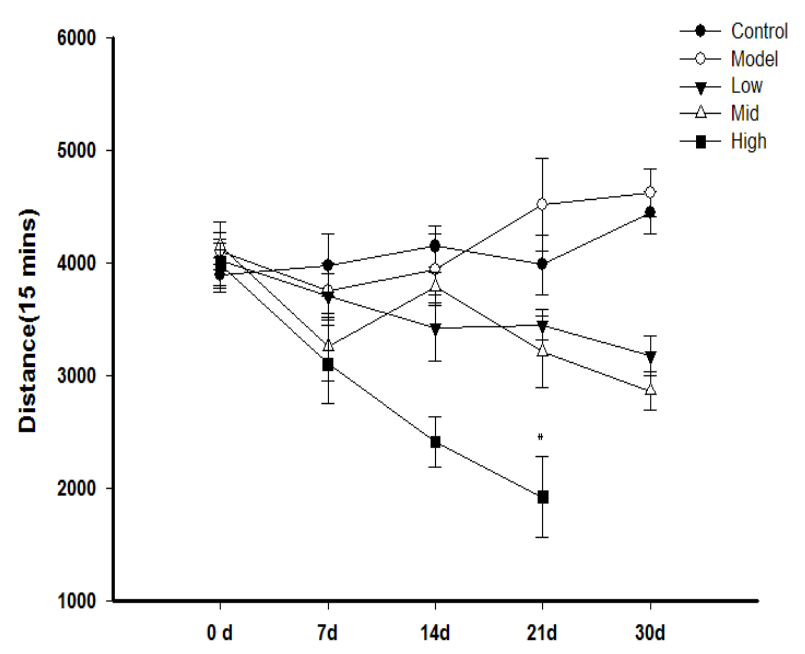

Figure.3. Effects of JDYH on physical movement. Rats ( $\mathrm{n}=12-$ 16) Each group chronic pretreatment JDYH $(0,14.12,28.24$, $56.48 \mathrm{~g} / \mathrm{kg}$, i.g.) for 30 days, then put in chambers for $15 \mathrm{~min}$ and the total distance was recorded (days $0,7,14,21$ and 30). Statistically significant differences are indicated by $*(p<0.05)$. 


\subsection{Representative individual response}

As shown in Fig 4 (A-B). Representative individual response records on day 21 after chronic treatment with JHYH. Each vertical tick mark indicates an speed. With the increase of dosage, the track of movement speed becomes less.

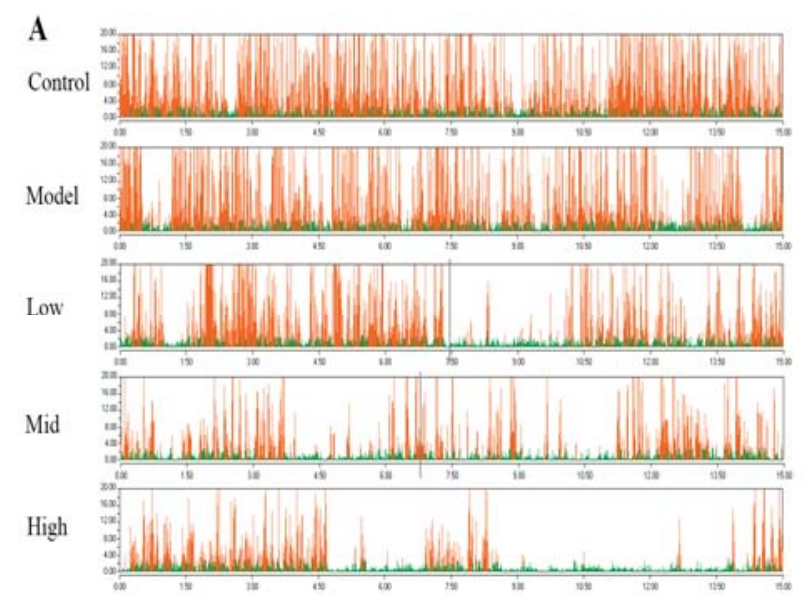

B

Control

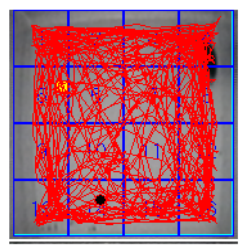

Model

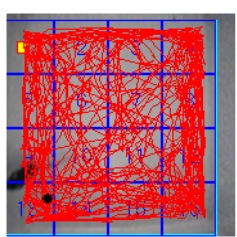

Low

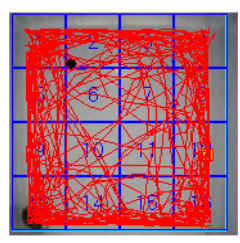

Mid

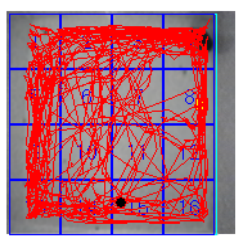

High

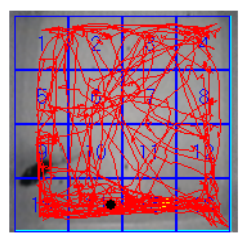

Fig.4. Representative indicidual response of JDYH on physical movement. (A) The speed of Representative individual response. (B) The show track of Representative individual response

\section{CONCLUSIONS}

In this study, we found that JDYH $(14.12,28.24 \mathrm{~g} / \mathrm{kg}$, i.g.) had no effect on body weight for 21 days. In addition, we also found that lower doses $(14.12,28.24 \mathrm{~g}$ $/ \mathrm{kg}$, i.g.) of JDYH generally had no effect on total distance traveled. Combined with our previous experimental results, This result indicate that JDYH inhibit METH-induced sensitization in mice without affecting motor activity and body weight.

In animal models, the spontaneous activity test which are considered in the classical models of drug addiction, examines the animal's ability to move, jump and walk, excluding the side effects of the JDYH tested. The main ingredient in JDYH is yanhusuo plants of the genus purple pansy yanhusuo (Corydalisyanhusuo W.T.Wang). Pharmacological studies have shown that corydalis corydalis and its main component l-tetrahydropalmatine (L-THP) can block the downregulation of dopaminereceptor in the striatum, nucleus accumbens, prefrontal cortex and other brain regions induced by methamphetamine[11,14-18].The expression of dopaminetransporter (DAT) can be up-regulated to reduce the level of DA and reverse the damage of DA neurons caused by methamphetamine, suggesting that the mechanism of corydus corydus and L-THP in the treatment of mental dependence is related to the downregulation of elevated DA and the up-regulation of the expressions of DAT and DAR[16, 19, 20]. These results indicates that corydalis corydalis has a promising application in the treatment of METH addiction, and can inhibit behavioral sensitization induced by METH by inhibiting the increase of DA level induced by METH in nucleus accumbens[17].

Our previous study suggests that JDYH may inhibit meth-induced behavioral sensitization by regulating the function of the DA system in the brain. Other components of JDYH have been shown to have sedativehypnotic[21-26], antiinflammatory[27-30] effects on the nervous system. In our experiment and combined with previous research, it is showed that the JDYH can improve the effects of METH addcition without inhibit physical movement.

\section{References}

1. Rubenis A J, Baker A L, Arunogiri S. Methamphetamine use and technology-mediated psychosocial interventions: A mini-review[J]. Addictive Behaviors, 2021(9):106881.

2. Perez F A, Blythe S, Wouldes T, et al. Prenatal Methamphetamine-impact on the mother and child -a review $[\mathrm{J}]$. Addiction.

3. Huang J, Zhang R, Wang S, et al. Methamphetamine and HIV-Tat Protein Synergistically Induce Oxidative Stress and Blood-Brain Barrier Damage via Transient Receptor Potential Melastatin 2 Channel[J]. Frontiers in Pharmacology, 2021, 12:619436. 
4. Austin A E, Gest C, Atkeson A, et al. Prenatal Substance Exposure and Child Maltreatment: A Systematic Review[J]. Child Maltreatment, 2021:1077559521990116.

5. Borrelli KN, Dubinsky KR, Szumlinski KK, et al. Intracranial self-stimulation and concomitant behaviors following systemic methamphetamine administration in Hnrnph1 mutant mice. Psychopharmacology (Berl). 2021.

6. Garcia-Fuentes D, Fernández-Fernández EP, Planet Nielsen N, et al. Attempted Suicide with Intravenous Methamphetamine and Chemsex. Rev Colomb Psiquiatr. 2020 .

7. Lee S O, Lee J E, Lee S, et al. Prevalence and patterns of illicit drug use in people with human immunodeficiency virus infection in Korea[J]. PLoS ONE, 2021, 16(4):e0249361.

8. Li WH, Li YH, Shan XG. Innovation of traditional Chinese medicine compounds and patent layout strategy with Lianhua Qingwen Formula as example[J]. Zhongguo Zhong Yao Za Zhi. 2021. 46(5): 1293-1300.

9. Chang SS, Huang HJ, Chen YC, et al. Two Birds with One Stone? Possible Dual-Targeting H1N1 Inhibitors from Traditional Chinese Medicine[J]. PLoS Computational Biology, 2011, 7(12):e1002315.

10. Li C, Tang LJ, Si YR, et al.Effects of Jieduyihao on Methamphetamine-induced Behavioral Sensitization in Mice[J]. Jianghan Univ.(Nat. Sci. Ed.)2019.41:57-65

11. Gong X, Yue K, Ma B, et al. Levotetrahydropalmatine, a natural, mixed dopamine receptor antagonist, inhibits methamphetamine selfadministration and methamphetamine-induced reinstatement[J]. Pharmacol Biochem Behav. 2016. 144: 67-72.

12. Ma B, Yue K, Chen L, et al. L-Stepholidine, a natural dopamine receptor D1 agonist and D2 antagonist, inhibits heroin-induced reinstatement[J]. Neuroscience Letters, 2014, 559:67-71.

13. Yue K, Ma B, Chen L, et al. L-Stepholidine, a naturally occurring dopamine D1 receptor agonist and D2 receptor antagonist, attenuates heroin selfadministration and cue-induced reinstatement in rats[J]. Neuroreport, 2014, 25(1):7.

14. Su HL, Zhu J, Chen Y J , et al. Roles of levotetrahydropalmatine in modulating methamphetamine reward behavior[J]. Physiology \& Behavior, 2013, 118:195-200.

15. Su H, Sun T, Wang $X$, et al. Levotetrahydropalmatine attenuates methamphetamine reward behavior and the accompanying activation of ERK phosphorylation in mice[J]. Neuroscience Letters, 2019, 714:134416.

16. Cao, Guofen, Zhang, et al. The inhibitory effect of levo-tetrahydropalmatine on the methamphetamineinduced spatial memory impairment in mice $[\mathrm{J}]$.
Neuroscience Letters: An International Multidisciplinary Journal Devoted to the Rapid Publication of Basic Research in the Brain Sciences, 2018, 672:34-39.

17. Yun, Jaesuk. 1-Tetrahydropalmatine inhibits methamphetamine-induced locomotor activity via regulation of 5-HT neuronal activity and dopamine D3 receptor expression[J]. Phytomedicine, 2014, 21(11):1287-1291.

18. Zhao N, Chen Y, Zhu J, et al. Levotetrahydropalmatine attenuates the development and expression of methamphetamine-induced locomotor sensitization and the accompanying activation of ERK in the nucleus accumbens and caudate putamen in mice[J]. Neuroscience. 2014. 258: 10110.

19. Y Li, Zhang T, Huai J, et al. Pharmacokinetic study of three different formulations of 1-tetrahydropalmatine in brain tissues of rats[J]. Biomedical Chromatography, 2021.

20. Xia X, He J, Liu B, et al. Targeting ER $\alpha$ degradation by L-Tetrahydropalmatine provides a novel strategy for breast cancer treatment[J]. International journal of biological sciences, 2020, 16(12):2192-2204.

21. Chun-Hay KO, Chi-Man K, Siu-Lung Y U, et al. Hypnotic effects of a novel anti-insomnia formula on Drosophila insomnia model[J]. Chinese Journal of Integrative Medicine, 2016, 22(005):335-343.

22. Ogawa Y, Fujii Y, Sugiyama R, et al. The role of the seven crude drug components in the sleeppromoting effect of Yokukansan[J]. Journal of Ethnopharmacology, 2016, 177:19-27.

23. Society of Critical Care Medicine, Chinese Medical Association. [Guideline for analgesia and sedation for patients in intensive care unit, China (2006)][J]. Zhonghua wai ke za zhi Chinese journal of surgery, 2006, 44(17):1158.

24. Akbari N, Asadimehr N, Kiani Z. The effects of licorice containing diphenhydramine solution on recurrent aphthous stomatitis: A double-blind, randomized clinical trial[J]. Complement Ther Med. 2020. 50: 102401.

25. Jin Z, Kim S, Cho $S$, et al. Potentiating Effect of Glabridin on GABA(A) Receptor-Mediated Responses in Dorsal Raphe Neurons[J]. Planta Medica, 2013, 79(15):1408-1412.

26. Bhatt C, Kanaki N, Nayak R, et al. Synergistic potentiation of anti-anxiety activity of valerian and alprazolam by liquorice[J]. Indian Journal of Pharmacology,45,2(2013-03-11), 2013, 45(2):202203.

27. Flagg A J . Traditional and Current Use of Ginseng[J]. Nursing Clinics of North America, 2020, 56(1).

28. Si WC, Li M, Wei J L, et al. The effects of angelica essential oil in three murine tests of anxiety[J]. Pharmacology Biochemistry \& Behavior, 2004, 79(2):377-382. 
29. Guo L Q, Taniguchi M, Chen Q Y, et al. Inhibitory Potential of Herbal Medicines on Human Cytochrome P450-Mediated Oxidation: Properties of Umbelliferous or Citrus Crude Drugs and Their Relative Prescriptions[J]. Japanese Journal of Pharmacology, 2001, 85( 4):399-408.

30. Zou W, Gong L, Zhou F, et al. Antiinflammatory effect of traditional Chinese medicine preparation Penyanling on pelvic inflammatory disease[J]. Journal of Ethnopharmacology, 2020, 266:113405. 